\title{
Abdominal volume index: a predictive measure in relationship between depression/anxiety and obesity
}

\author{
Said Hadi ${ }^{1,2}$, Mehrnaz Momenan ${ }^{3}$, Kasra Cheraghpour ${ }^{4}$, Nadia Hafizi ${ }^{5}$, Niloufar Pourjavidi ${ }^{6}$, \\ Mahsa Malekahmadi ${ }^{7}$, Mona Foroughi ${ }^{8}$, Meysam Alipour ${ }^{9}$
}

1. Department of Health, AJA University of medical sciences, Tehran, Iran.

2. Food Security Research Center, Isfahan University of Medical Sciences, Isfahan, Iran.

3. Nutrition and Metabolic Disease Research Center, ShahidBeheshti University of Medical Sciences, Tehran, Iran.

4. Faculty of Medicine, Iran University of Medical Sciences, Tehran, Iran.

5. Department of Clinical Nutrition, School of Nutritional Sciences and Dietetics, Tehran University of Medical Sciences, Tehran, Iran.

6. Department of Nutrition, College of Food Science and Technology, Science and Research Branch, Islamic Azad University, Tehran, Iran.

7. Student Research Committee, Department of Nutrition, School of Medicine, Mashhad University of Medical Sciences, Mashhad, Iran.

8. Specialty and Subspecialty Hospital of Khatam-ol-Anbia, Tehran, Iran.

9. Alimentary Tract Research Center,Imamkhomeini Hospital Clinical Research Development Unit, Ahvaz Jundishapur

University of Medical Sciences, Ahvaz, Iran.

\begin{abstract}
Background: Obesity is a risk factor for mood disorder (such as depression and anxiety). We aimed to assess application of A Body Shape Index (ABSI) and abdominal volume index (AVI), as new indices of obesity to evaluate the relationship between obesity and depression/anxiety.

Methods: This cross sectional study was conducted on 307 overweight and obese women (249 females, 58 males) 20-60 years in Iran in 2017-2018. The anthropometric measures including weight, waist circumference, hip circumference, body fat and derived values of body mass index, waist-hip ratio, AVI and ABSI were evaluated. HADS questionnaire for depression and anxiety completed.

Results: Prevalence of depression was $36.1 \%$ in women; men $24.1 \%$; overweight $28.1 \%$; obese $36.5 \%$ and central obesity $33.7 \%$. Anxiety was apparent in $27.1 \%$ of overweight $30.3 \%$ obese and $29.6 \%$ central obesity. People with depression and anxiety had higher WC, BF and AVI. ABSI had no significant correlation with depression/anxiety. The odds of depression (1.06; 95\% CI, 1.02-1.12) and anxiety (1.06; 95\% CI, 1.01-1.11) were elevated with increase AVI.

Conclusion: Our results suggested that AVI as an indirect measure of abdominal obesity along with WC and BF could be useful in predicting the relationship between obesity and depression/anxiety.

Keywords: Abdominal volume index; anxiety; depression.

DOI: https://dx.doi.org/10.4314/ahs.v20i1.31

Cite as: Hadi S, Momenan M, Cheraghpour K, Hafizi N, Pourjavidi N, Malekahmadi M, et al. Abdominal volume index: a predictive measure in relationship between depression/ anxiety and obesity Afri Health Sci. 2020;20(1):257-65.https:/ / dx.doi.org/10.4314/abs.v20i1.31
\end{abstract}

\section{Corresponding author:}

Said Hadi,

Department of Health, AJA University of Medical

Sciences, Tehran, Iran.

Email: s.hadinu@yahoo.com;

MeysamAlipour,

Alimentary Tract Research Center, Imamkhomeini

Hospital Clinical Research Development Unit,

Ahvaz Jundishapur University of Medical Sciences,

Ahvaz, Iran. P. O. Box: 159613-5715794, Ahvaz, Iran.

Tel: +98-6133367543, Fax: +98-6133720299,

Email: meysam.aalipour@yahoo.com

\section{Introduction}

Excessive body fat deposition which is defined as obesity has a dramatic growing trend worldwide and it could increase all-cause mortality ${ }^{1}$. Obesity is considered as a chronic and complex disease which contributes in a wide range of adverse health outcomes such as cardiovascular, visual and psychiatric disorders ${ }^{2-4}$.

Depressive disorders are the major psychiatric problem worldwide which will account $11 \%$ of total burden of disease by 2020 according to world health organization report $^{5}$. The interrelationship between obesity and depression frequently has been studied in the literature although still it is not fully understood that how they are 
linked? Some investigations suggest that depression is more prevalent among obese people particularly females while paradoxically there is some evidence linking obesity to lower degree of depressive symptoms and anxiety ${ }^{6-8}$. However there are several proposed mechanisms on the pathways explaining the obesity and depression association among them dysfunction in HPA axis has attracted much interest ${ }^{9,10}$. Actually it has been suggested that depression and anxiety can induce the activity of HPA axis which in turn increases adrenal cortisol secretion ${ }^{11}$. Some evidence has also supported the obesity, particularly abdominal type, to be developed following over-activation of HPA axis ${ }^{12}$.

Many studies seeking the correlation between obesity and depression/anxiety have used BMI as a predictor index of higher fat accumulation while it has been confirmed that however BMI is the best tool for body fat estimation it has some limitations in indication of how this fat mass is distributed over the body ${ }^{13}$. Some evidence account fat distribution particularly abdominal adiposity as a more predictive index for the association between obesity and diseases specially mood illnesses including depression and anxiety ${ }^{14}$. Zhao et al study suggested that abdominal obesity among overweight and obese individuals was significantly associated with icreased depressive symptoms ${ }^{15}$. Lee et al reported that depressive mood is associated with visceral fat, not with subcutaneous fat, in overweight premenopausal women ${ }^{16}$. There are some indices locating fat mass including Waist-height ratio (WHtR), Waist-hip ratio (WHR) and the newer ones like a body shape index (ABSI) and abdominal volume index (AVI) ${ }^{17,18}$. In current study we hypothesized that these new indices are more useful in detecting the potential link between obesity and depression/anxiety.

\section{Methods}

In the cross sectional study, participants selected by simple random sampling from Golestan referral and governmental Hospital of Ahvaz Jundishapur University of Medical science in Ahvaz, Iran from October 2017 to March 2018. Among eligible participants in this study, Forty-eight individuals, including Patients with psychological diseases other than depressive disorders and people consuming alcohol or psychotropic drugs were excluded from our investigation. Finally, 307 individuals (249 females and 58 males) between 18 to 60 years of age with BMI above $25 \mathrm{~kg} / \mathrm{m}^{2}$ and history of failure to lose extra body weights, to be enrolled to this study. The study was approved by the ethical committee of AJA University of Medical Sciences. At the beginning all the entrants completed written informed consent and another demographic questionnaire. Sample size was calculated according to previous study ${ }^{15}$ and using the following formula: Sample size $=$ D $\left[\right.$ Z2 $\left.1_{-\alpha / 2} \times \mathrm{p} \times(1-\mathrm{p})\right] \mathrm{d} 2$.

$\mathrm{D}=$ design effect of 2 was used to account for increased variance due to the cluster sampling technique. $\mathrm{Z1}-\alpha=$ the $z$-score corresponding to the desired confidence level of the estimate. A 95\% confidence level $(95 \% \mathrm{CI})$ was chosen, corresponding to Z1- $\alpha=1.96$.

Body weight (to the nearest $0.1 \mathrm{~kg}$ ) and standing height (to the nearest $0.1 \mathrm{~cm}$ ) were measured (Inbody230, Biospace, Korea). The scale was calibrated before each measurement. BMI was calculated with using weight $(\mathrm{kg}) \mathrm{di}-$ vided by height (m) squared. Waist circumferences (WC) and hip circumferences (HC) measurement was evaluated according to the protocol presented in another study ${ }^{19}$. The WHR was obtained by dividing WC to HC. A body shape index $(\mathrm{ABSI})=\mathrm{WC} /(\mathrm{BMI} 2 / 3$ height $1 / 2)$ and $\mathrm{ab}-$ dominal volume index (AVI) $=[2 \mathrm{~cm}$ (waist) $2+0.7 \mathrm{~cm}$ (waist-hip)2]/1,000, are new indices of body fat percentage and abdominal fat accumulation which we calculated according to previous studies ${ }^{20,21}$. Moreover tetra polar Bioelectrical Impedance Analysis (BIA) was applied to evaluate body fat and lean body mass in participants. Evaluation of depressive symptoms was done using Hospital Anxiety and Depression Scale (HADS) which helps patients to assess their symptoms of both depression and anxiety during the last week they passed by themselves. This scale is a questionnaire consists of two groups of questions, seven for each part, indicating anxiety and depression in a clinical setting. Each subscale of HADS has an overall score range 0 to 21 which the higher score indicates the higher severity of anxiety or depression as follows: 0-7 no symptoms, 8-10 mild, 11-14 moderate and 14-21 severe ${ }^{22}$. An observer was used to evaluate the equipment, methods and assessment technics used in this study.

\section{Statistical analyses}

All the analyses were performed using IBM SPSS statistics for windows version 21.0 (IBM Corp, 2012). Kolmogorov-Smirnov test was used to examine whether the variables have normal distribution or not. For compare means over two groups, Kruskal-Wallis and One-Way ANOVA tests were used. Chi square, Wilcoxon signed- 
rank and independent samples $t$ tests were used to compare means between groups. Spearman and Pearson tests were used to assess correlation markers for anthropometric measurements. $\mathrm{P}<0.05$ was considered as statistical significant in all the analyses.

\section{Results}

This study included 249 females and 58 males aged be- tween 18 to 60 years (mean $39.98 \pm 11.77$ ). We didn't have missing value in our study. Means of calculated BMI and ABSI for all the participants were 32.83 \pm 5.06 and $0.0100 \pm 0.002$ respectively. We showed the distribution of the values as median for WC, percentage of body fat, and AVI ( $\mathrm{cm}, 38.25 \%$ and 22.05 respectively). Table 1 has summarized analysis of anthropometric measurements and adiposity indices among quartiles of ABSI.

Table 1. Anthropometric characteristic of participants for anxiety status according to HADS score

\begin{tabular}{cccccc}
\hline Variables & \multicolumn{5}{c}{ ABSI } \\
\hline & $\mathrm{Q} 1$ & $\mathrm{Q} 2$ & $\mathrm{Q} 3$ & $\mathrm{Q} 3$ & $\mathrm{P}-\mathrm{V}$ \\
\hline Age, years & $39.3 \pm 11.2$ & $39.1 \pm 10.9$ & $40.7 \pm 11.7$ & $40.6 \pm 13.1$ & 0.75 \\
Weight $(\mathrm{Kg})$ & $107.6 \pm 15$ & $90.4 \pm 9.3$ & $81.4 \pm 7.2$ & $72.5 \pm 7$ & $<0.001$ \\
BMI $\left(\mathrm{kg} / \mathrm{m}^{2}\right)$ & $39.5 \pm 3.8$ & $33.6 \pm 1.8$ & $30.7 \pm 1.5$ & $27.4 \pm 1.8$ & $<0.001$ \\
WC* $(\mathrm{cm})$ & $120(111-127.75)$ & $107(100.5-113)$ & $102(98-107)$ & $97.5(92-103)$ & $<0.001^{* *}$ \\
HC $(\mathrm{cm})$ & $119.7 \pm 11.3$ & $111.6 \pm 8.3$ & $108.4 \pm 6.2$ & $103.8 \pm 5.9$ & $<0.001$ \\
WHR & $1.00 \pm 0.11$ & $0.96 \pm 0.09$ & $0.94 \pm 0.07$ & $0.94 \pm 0.08$ & $<0.001$ \\
BFP* & $42.2(38.3-44.9)$ & $39.7(35.1-41.7)$ & $38.4(35.2-39.9)$ & $35(31.8-36.9)$ & $<0.001 * *$ \\
AVI & $29(24.6-32.6)$ & $22.8(20.2-25.5)$ & $20.8(22.8-19.2)$ & $19(16.9-21.2)$ & $<0.001^{* *}$ \\
\hline
\end{tabular}

BMI; Body Mass Index, WC; Waist Circumference, HC; Hip Circumference, WHR; Waist-hip ratio, PBF; percentage body fat, ABSI; A Body Shape Index, AVI; abdominal volume index

*These variables are expressed as median and interquartile range and others are expressed as mean $\pm \mathrm{SD}$.

** P values were derived from Kruskal-Wallis and others from One-Way ANOVA.

Characteristics of the study population according to status of depression using HADS-depression score are shown in Table 2. The results of our study showed that $36.1 \%$ of women and $24.1 \%$ of men, $28.1 \%$ of overweight and $36.5 \%$ of obese subjects, $33.7 \%$ of subjects with central obesity and $38.5 \%$ of ones without central obesity had some degrees of depression based on HADS-depression score. Moreover $76.6 \%$ of people with depression had apparent symptoms of anxiety which was proved using scores resulted from HADS-anxiety questionnaire (Table 2). 
Table 2. Qualitative characteristics of study population according to status of anxiety and depression

\begin{tabular}{|c|c|c|c|c|c|c|c|}
\hline \multicolumn{2}{|c|}{ Variables } & \multicolumn{3}{|c|}{ Anxiety } & \multicolumn{3}{|c|}{ Depression } \\
\hline & & $\begin{array}{c}\text { No } \\
(\mathrm{N}=217)\end{array}$ & $\begin{array}{c}\text { Yes } \\
(\mathrm{N}=90)\end{array}$ & $\begin{array}{c}\text { P- } \\
\text { value* }\end{array}$ & $\begin{array}{c}\text { No } \\
(\mathrm{N}=203)\end{array}$ & $\begin{array}{c}\text { Yes } \\
(\mathrm{N}=104)\end{array}$ & P-value* \\
\hline Anxiety/ & No, n (\%) & $\begin{array}{c}182 \\
(89.7 \%)\end{array}$ & $21(10.3 \%)$ & $0.001^{* *}$ & $182(83.8 \%)$ & $35(16.2 \%)$ & $0.001^{* *}$ \\
\hline Depression & Yes, n (\%) & $35(33.7 \%)$ & $69(66.3 \%)$ & & $21(23.3 \%)$ & $69(76.6 \%)$ & \\
\hline \multirow[t]{2}{*}{ Sex } & Male, n (\%) & $46(79.3 \%)$ & $12(20.7 \%)$ & 0.15 & $44(75.9 \%)$ & $14(24.1 \%)$ & 0.08 \\
\hline & Female, n (\%) & $\begin{array}{c}171 \\
(68.7 \%)\end{array}$ & $78(31.3 \%)$ & & $159(63.9 \%)$ & $90(36.1 \%)$ & \\
\hline \multirow[t]{3}{*}{ Age groups } & $<40, \mathrm{n}(\%)$ & $\begin{array}{c}113 \\
(72.0 \%)\end{array}$ & $\begin{array}{c}44 \\
(28.0 \%)\end{array}$ & 0.87 & $105(66.5 \%)$ & $53(33.5 \%)$ & 0.27 \\
\hline & $40-<60, \mathrm{n}(\%)$ & $90(69.2 \%)$ & $\begin{array}{c}40 \\
(30.8 \%)\end{array}$ & & $88(68.2 \%)$ & $41(31.8 \%)$ & \\
\hline & $\geq 60, \mathrm{n}(\%)$ & $14(70.0 \%)$ & $6(30.0 \%)$ & & $10(50 \%)$ & $10(50 \%)$ & \\
\hline \multirow[t]{2}{*}{ BMI } & $\begin{array}{c}\text { Overweight, } \mathrm{n} \\
(\%)\end{array}$ & $70(72.9 \%)$ & $26(27.1 \%)$ & 0.47 & $69(71.9 \%)$ & $27(28.1 \%)$ & 0.15 \\
\hline & Obese, n (\%) & $\begin{array}{c}147 \\
(69.7 \%)\end{array}$ & $\begin{array}{c}64 \\
(30.3 \%)\end{array}$ & & $134(63.5 \%)$ & $77(36.5 \%)$ & \\
\hline \multirow[t]{2}{*}{ WC } & $\begin{array}{c}\text { No Central } \\
\text { Obesity, n (\%) }\end{array}$ & $19(70.4 \%)$ & $8(29.6 \%)$ & 0.28 & $8(61.5 \%)$ & $5(38.5 \%)$ & 0.72 \\
\hline & $\begin{array}{c}\text { Central Obesity, } \\
\text { n (\%) }\end{array}$ & $\begin{array}{c}198 \\
(76.9 \%)\end{array}$ & $\begin{array}{c}92 \\
(23.1 \%)\end{array}$ & & $195(66.3 \%)$ & $99(33.7 \%)$ & \\
\hline
\end{tabular}

BMI; Body Mass Index, WC; Waist Circumference *P -values were derived from chi square test

The anthropometric measurements of samples for status of anxiety and depression according to HADS-anxiety score are presented in table 3. Application of HADS-anxiety for seeking symptoms of anxiety showed that $31.3 \%$ of women and $20.7 \%$ of men were anxious. Furthermore $27.1 \%$ of overweight and $30.3 \%$ of obese subjects, and also $29.6 \%$ and $23.1 \%$ of participants with or without central obesity experienced some degrees of anxiety.
The investigation of correlation between depression/ anxiety HADS scores and anthropometric indices measurements indicated that people with anxiety had higher WC (107 vs. 103), percentage of body fat (39 vs. 38.05) and AVI (22.89 vs. 21.21) compare to normal group. In addition, individuals with high score of depression had higher WC (108 vs. 103$)$ and AVI (23.32 vs. 21.21$)$ compare to normal individuals (Table 3 ). 
Table 3. Demographic and anthropometric characteristic of participants for status of anxiety and depression according to HADS anxiety score

\begin{tabular}{|c|c|c|c|c|c|c|}
\hline \multirow[t]{2}{*}{ Variables } & \multicolumn{3}{|c|}{ Anxiety status } & \multicolumn{3}{|c|}{ Depression status } \\
\hline & Normal (n=217) & Anxious ( $(\mathrm{n}=90)$ & $\mathrm{P}-\mathrm{V}$ & Normal (n=203) & Depression $(n=104)$ & $\mathrm{P}-\mathrm{V}$ \\
\hline Age (years) & $40.02 \pm 11.76$ & $39.89 \pm 11.92$ & 0.91 & $39.85 \pm 11.69$ & $40.24 \pm 12.03$ & 0.79 \\
\hline $\begin{array}{l}\text { Weight } \\
(\mathrm{Kg})\end{array}$ & $87.33 \pm 16.31$ & $89.67 \pm 16.79$ & 0.21 & $87.22 \pm 16.25$ & $89.55 \pm 16.83$ & 0.26 \\
\hline $\begin{array}{l}\text { BMI } \\
\left(\mathrm{kg} / \mathrm{m}^{2}\right)\end{array}$ & $32.59 \pm 4.97$ & $33.41 \pm 5.26$ & 0.23 & $32.51 \pm 5.11$ & $33.46 \pm 4.69$ & 0.14 \\
\hline $\mathrm{WC} *(\mathrm{~cm})$ & $103(97-112)$ & $107(99-117.75)$ & $0.02 * *$ & $103(98-112)$ & $108(98.25-119.25)$ & $0.02 * *$ \\
\hline $\mathrm{HC}(\mathrm{cm})$ & $110.27 \pm 9.81$ & $112.51 \pm 10.38$ & 0.08 & $110.26 \pm 10.09$ & $112.22 \pm 9.78$ & 0.11 \\
\hline WHR & $0.96 \pm 0.10$ & $0.97 \pm 0.09$ & 0.43 & $0.95 \pm 0.09$ & $0.97 \pm 0.09$ & 0.41 \\
\hline $\mathrm{PBF}^{*}(\%)$ & $38.05(33.67-40.75)$ & $39(35.12-42.25)$ & $0.03 * *$ & $\begin{array}{c}38.1(33.55- \\
41.05)\end{array}$ & $38.8(34.8-42.1)$ & $0.13 * *$ \\
\hline ABSI & $0.01 \pm 0.002$ & $0.001 \pm 0.002$ & 0.75 & $0.0102 \pm 0.002$ & $0.0098 \pm 0.002$ & 0.35 \\
\hline $\mathrm{AVI}^{*}$ & $21.21(18.81-25.08)$ & $22.89(19.60-27.73)$ & $0.02 * *$ & $\begin{array}{c}21.21(19.2- \\
25.08)\end{array}$ & $23.32(19.30-28.44)$ & $0.02 * *$ \\
\hline $\begin{array}{l}\text { Depression } \\
\text { score* }\end{array}$ & $5(3-6)$ & $9(8-12)$ & $0.001 * *$ & $3(2-5)$ & $9(7-12)$ & $0.001 * *$ \\
\hline
\end{tabular}

BMI; Body Mass Index, WC; Waist Circumference, HC; Hip Circumference, WHR; Waist-hip ratio, PBF; percentage body fat, ABSI; A Body Shape Index, AVI; abdominal volume index

*These variables are expressed as median and interquartile range and others are expressed as mean \pm standard deviation

** $\mathrm{P}$-values were derived from Wilcoxon signed-rank and others from test independent $t$ test

Table 4 show the logistic regression analysis used to examine the relationship between anthropometric indexes and depression or anxiety. Depression and anxiety had a significant positive relationship with $\mathrm{WC}, \mathrm{BF}, \mathrm{WHR}$ and AVI. Table 5 show that the $\mathrm{BMI}, \mathrm{WC}, \mathrm{BF}, \mathrm{BF} \%$ have a significant correlation with AVI (positively) and ABSI (negatively).
We set median of AVI as its cut off and, accordingly, we performed regression analysis for other measurements as described in Table 4. Even after adjustment for age and height being obese (BMI more than $30 \mathrm{~kg} / \mathrm{m}^{2}$ ) had the greatest effects on AVI and smallest effect belonged to being at a BMI ranges 25 to $29.9 \mathrm{~kg} / \mathrm{m}^{2}$. 
Table 4. Logistic regression model predicting depression and anxiety according to anthropometric indices

\begin{tabular}{ccccccc}
\hline Variables & \multicolumn{5}{c}{ Anxiety } & Depression \\
\cline { 2 - 6 } & OR & CI & P-V & OR & CI & P-V \\
\hline Weight $(\mathrm{kg})$ & 1.019 & $(1.002-1.037)$ & 0.03 & 1.020 & $(1.003-1.037)$ & 0.01 \\
Height (cm) & 1.047 & $(1.000-1.097)$ & 0.05 & 1.036 & $(1.007-1.047)$ & 0.11 \\
WC (cm) & 1.028 & $(1.008-1.050)$ & 0.007 & 1.027 & $(0.992-1.083)$ & 0.01 \\
HC (cm) & 1.016 & $(0.989-1.043)$ & 0.25 & 1.013 & $(1.007-1.047)$ & 0.34 \\
Anxiety & 1.600 & $(1.428-1.792)$ & 0.001 & 1.495 & $(1.363-1.640)$ & 0.001 \\
LBM (kg) & 1.027 & $(0.993-1.063)$ & 0.11 & 1.037 & $(1.003-1.072)$ & 0.03 \\
BF (kg) & 1.033 & $(1.004-1.063)$ & 0.02 & 1.029 & $(1.00-1.058)$ & 0.04 \\
PBF (\%) & 1.052 & $(0.993-1.113)$ & 0.08 & 1.034 & $(0.980-1.092)$ & 0.22 \\
BMI (kg/m $)$ & 1.038 & $(0.988-1.089)$ & 0.13 & 1.043 & $(0.995-1.093)$ & 0.08 \\
WHR & 119.284 & $(3.896-3652.5)$ & 0.006 & 119.044 & $(4.315-328.54)$ & 0.005 \\
ABSI & 0.000 & $(0.0-4.1 \mathrm{E}+33)$ & 0.51 & 0.00 & $(0.00-3.593 \mathrm{E}+16)$ & 0.19 \\
AVI & 1.063 & $(1.016-1.112)$ & 0.009 & 1.061 & $(1.015-1.109)$ & 0.01 \\
\hline Central obesity & 1.577 & $(0.419-5.929)$ & 0.50 & 0.891 & $(0.281-2.82)$ & 0.84 \\
\hline
\end{tabular}

BMI; Body Mass Index, WC; Waist Circumference, HC; Hip Circumference, WHR; Waist-hip ratio, LBM; Lean Body Mass, PBF; percentage body fat, ABSI; A Body Shape Index, AVI; abdominal volume index, CI; Confidence interval

P-Values were adjusted for age and gender

Table 5. Correlation markers for anthropometric measurements

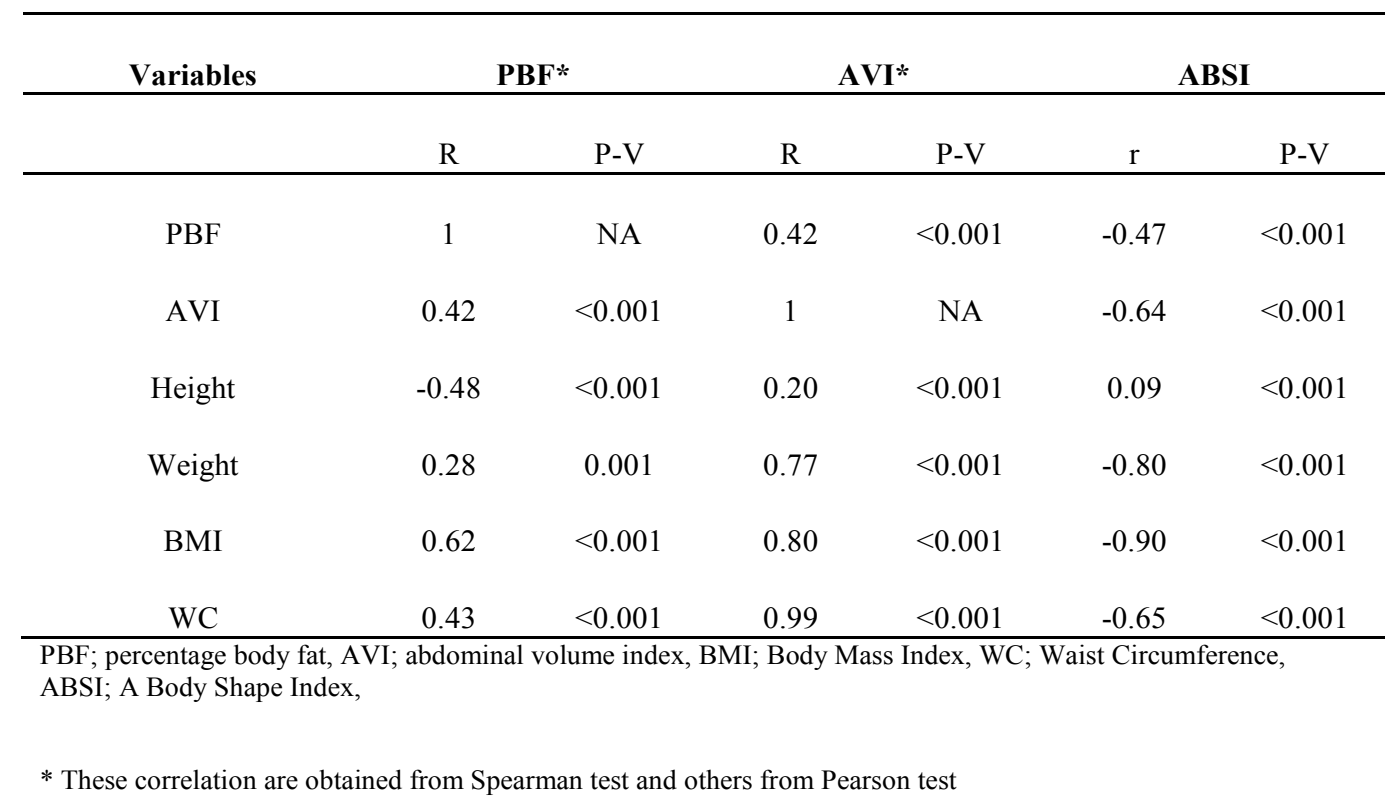




\section{Discussion}

There is a large body of literature assessing the interrelationship between obesity and mood disorders ${ }^{6,8,10}$. It has been suggested that there are a reciprocal link between depression / anxiety and obesity. A meta-analysis reported that obesity increased the risk of depression, and depression increased the odds for developing obesity ${ }^{23}$. On the other hand, there are various tools and indicators with different performance for assessing obesity. Recently, many studies have been conducted to introduce the best anthropometric measure predicting the relationship between obesity and mood disorder such as depression and anxiety.

In our study, we did not find any significant correlation between BMI and depression or anxiety. BMI is a conventional and easy tool for indication of overweight and obesity but it has some limitations include inability to differentiate the adipose tissue and lean body mass and also significant differences in the BMI efficiency between ethnic groups ${ }^{24,25}$. These limitations may be more in men due to higher muscle mass compare to women. Several studies reported that BMI was a significant predictor of depression in females but not in males ${ }^{26,27}$. It seems that other anthropometric indices are more effective to evaluate the relationship between obesity and depression/ anxiety status. Similar to our findings, Guedes et al suggested that the body fat percentage and not BMI was associated with an increased severity of anxiety and depressive symptoms based on HADS scores ${ }^{28}$.

Failing in indication of body shape by the BMI formed the basics of studies seeking new tools for locating body central fat including WC, ABSI and AVI. We hypothesized that new anthropometric indices including AVI and ABSI could be more useful because of the proposed ability to indicate abdominal fat accumulation. To the authors' knowledge this was the first investigation assessing the application of ABSI and AVI in clarification of relationship between obesity and depression or anxiety.

ABSI has obtained from standardization of WC to weight and height and proposed as a new index for estimation of death hazard due to obesity. High values of ABSI could imply that fat is over deposited in abdominal area and the fraction of lean body mass is diminished in periphery ${ }^{20}$. In comparison to normal subjects neither for depression nor for anxiety, we observed difference in mean ABSI.
Moreover ABSI had no significant correlation with BMI, $\mathrm{BF}$, and $\mathrm{BF} \%$ in our samples.

Our results also showed that AVI is higher in people with depression/anxiety. AVI takes place among the best indicators of abdominal fat deposition ${ }^{29}$. In consistent with the Ehrampoush et al. comparative study on various anthropometric tools for exploring adiposity we also suggest that AVI is strongly correlated with WC and $\mathrm{BF}$ which are predictive for accumulation of fat mass in central area of human body ${ }^{17}$. Abdominal adipose tissue induces immune system activation following release of cytokines and other regulatory molecules which in turn trigger inflammatory pathways in downstream ${ }^{30,31}$. Depression symptoms could be aggravated as a result of systemic inflammation so it has much of importance to concentrate on central adiposity when we are talking about the relationship between obesity and depression/ anxiety $^{32}$. Some other mechanisms have been suggested for the linkage between abdominal obesity and depression among them dysregulation of hypothalamic-pituitary-adrenocortical (HPA) axis resulted by reduction in glucocorticoid receptors (GR) and over secretion of cortisol could be emphasized ${ }^{33}$.

Our study had some limitations: The cross-sectional nature of this study made it difficult to conclude a causal relationship. Indeed it is not clearly understood whether depression or anxiety influenced the possibility of overweight and obesity or people with high amount of body fat appear with symptoms of depression or anxiety. Secondly, we could not find any correlation between ABSI and depression which could partly be due to small number of sample and confounders effect. Moreover it would be better if we had a control group with normal BMI to find a dose response for observed relationship between abdominal obesity and depression/anxiety. To the best of our knowledge, the study was the first to report the relationship between depression/anxiety and AVI and ABSI in among overweight and obese women.

\section{Conclusion}

We concluded that AVI could be a better anthropometric measure for indication of relationship between abdominal obesity and depression/anxiety in a small population. The continuing increases in the global prevalence of overweight and obesity suggest that mental health sta- 
tus should be screened and evaluated in obese individuals especially people with central obesity. A routine anthropometric index like BMI has some limitations to assess central obesity. Our results suggest that the AVI is useful for evaluating obesity in depression/anxiety.

\section{Acknowledgments}

We are thankful to Aja University of Medical Science, Tehran, Iran.

\section{Conflict of interests}

The authors declare no conflict of interest.

\section{References}

1. Thomas EL, Frost G, Taylor-Robinson SD, Bell JD. Excess body fat in obese and normal-weight subjects. Nutr Res Rev. 2012 Jun;25(1):150-61.

2. Mohammadzadeh M, Mohammadzadeh V, Shakiba M, Motevalli M, Abedini A, Kadivar S, et al. Assessing the Relation of Epicardial Fat Thickness and Volume, Quantified by 256-Slice Computed Tomography Scan, With Coronary Artery Disease and Cardiovascular Risk Factors. Arch Iran Med. 2018 Mar 1;21(3):95-100.

3. Graupensperger S, Sweet SN, Evans MB. Multimorbidity of overweight and obesity alongside anxiety and depressive disorders in individuals with spinal cord injury. J Spinal Cord Med. 2018 Sep 5:1-9.

4. Ghanavati M, Behrooz M, Rashidkhani B, Ashtray-Larky D, Zameni SD, Alipour M. Healthy Eating Index in Patients With Cataract: A Case-Control Study. Iran Red Crescent Med J. 2015 Oct 28;17(10):e22490.

5. Reddy MS. Depression: the disorder and the burden. Indian J Psychol Med. 2010 Jan;32(1):1-2.

6. de Wit L, Luppino F, van Straten A, Penninx B, Zitman F, Cuijpers P. Depression and obesity: a meta-analysis of community-based studies. Psychiatry Res. $2010 \mathrm{Jul}$ 30;178(2):230-5.

7. Jorm AF, Korten AE, Christensen H, Jacomb PA, Rodgers B, Parslow RA. Association of obesity with anxiety, depression and emotional well-being: a community survey. Aust N Z J Public Health. 2003;27(4):434-40.

8. Ma J, Xiao L. Obesity and depression in US women: results from the 2005-2006 National Health and Nutritional Examination Survey. Obesity (Silver Spring). 2010 Feb;18(2):347-53.

9. Marniemi J, Kronholm E, Aunola S, Toikka T, Mattlar CE, Koskenvuo M, et al. Visceral fat and psychosocial stress in identical twins discordant for obesity. J Intern Med. 2002 Jan;251(1):35-43.

African Health Sciences Vol 20 Issue 1, March, 2020
10. McElroy SL, Kotwal R, Malhotra S, Nelson EB, Keck PE, Nemeroff CB. Are mood disorders and obesity related? A review for the mental health professional. J Clin Psychiatry. 2004; 65(5):634-51.

11. Esmaeili MH, Bahari B, Salari AA. ATP-sensitive potassium-channel inhibitor glibenclamide attenuates HPA axis hyperactivity, depression- and anxiety-related symptoms in a rat model of Alzheimer's disease. Brain Res Bull. 2018 Mar;137:265-276.

12. Agustí A, García-Pardo MP, López-Almela I, Campillo I, Maes M, Romaní-Pérez M, et al. Interplay Between the Gut-Brain Axis, Obesity and Cognitive Function. Front Neurosci. 2018 Mar 16;12:155.

13. Vanderwall C, Eickhoff J, Randall Clark R, Carrel AL. BMI $z$-score in obese children is a poor predictor of adiposity changes over time. BMC Pediatr. 2018 Jun 8;18(1):187.

14. Esmaeilzadeh S, Farzizadeh R, Kalantari HA, Mahmoudi A, Bilehsavar OY, Mehranpour A. Central or overall obesity: which one is a better predictor of depressive symptoms in children, adolescents, and youths? Eat Weight Disord. 2018 Feb;23(1):117-123.

15. Zhao G, Ford ES, Li C, Tsai J, Dhingra S, Balluz LS. Waist circumference, abdominal obesity, and depression among overweight and obese U.S. adults: National Health and Nutrition Examination Survey 2005-2006. BMC Psychiatry. 2011 Aug 11;11:130.

16. Lee ES, Kim YH, Beck SH, Lee S, Oh SW. Depressive mood and abdominal fat distribution in overweight premenopausal women. Obes Res. 2005 Feb;13(2):320-5.

17. Ehrampoush E, Arasteh P, Homayounfar R, Cheraghpour M, Alipour M, Naghizadeh MM, et al. New anthropometric indices or old ones: Which is the better predictor of body fat? Diabetes Metab Syndr. 2017 Oct Dec;11(4):257-263.

18. Ashtary-Larky D, Daneghian S, Alipour M, Rafiei H, Ghanavati M, Mohammadpour R, et al. Waist Circumference to Height Ratio: Better Correlation with Fat Mass Than Other Anthropometric Indices During Dietary Weight Loss in Different Rates, Int J Endocrinol Metab. In Press(In Press):e55023.

19. Ashtary-Larky D, Ghanavati M, Lamuchi-Deli N, Payami SA, Alavi-Rad S, Boustaninejad M, et al. Rapid Weight Loss vs. Slow Weight Loss: Which is More Effective on Body Composition and Metabolic Risk Factors? Int J Endocrinol Metab. 2017 May 17;15(3):e13249.

20. Krakauer NY, Krakauer JC. A new body shape index predicts mortality hazard independently of body mass index. PLoS One. 2012;7(7):e39504. 
21. Guerrero-Romero F, Rodríguez-Morán M. Abdominal volume index. An anthropometry-based index for estimation of obesity is strongly related to impaired glucose tolerance and type 2 diabetes mellitus. Arch Med Res. 2003 Sep-Oct;34(5):428-32.

22. Villoria E, Lara L. Assessment of the Hospital Anxiety and Depression Scale for cancer patients. Rev Med Chil. 2018 Mar;146(3):300-307.

23. Luppino FS, de Wit LM, Bouvy PF, Stijnen T, Cuijpers P, Penninx BW, et al. Overweight, obesity, and depression: a systematic review and meta-analysis of longitudinal studies. Arch Gen Psychiatry. 2010 Mar;67(3):220-9.

24. Javed A, Jumean M, Murad MH, Okorodudu D, Kumar S, Somers VK, et al. Diagnostic performance of body mass index to identify obesity as defined by body adiposity in children and adolescents: a systematic review and meta-analysis. Pediatr Obes. 2015 Jun;10(3):234-44.

25. WHO Expert Consultation. Appropriate body-mass index for Asian populations and its implications for policy and intervention strategies. Lancet. 2004 Jan 10;363 (9403):157-63.

26. Wild B, Herzog W, Lechner S, Niehoff D, Brenner H, Müller H, et al. Gender specific temporal and cross-sectional associations between BMI-class and symptoms of depression in the elderly. J Psychosom Res. 2012;72:276-382. 27. Lim W, Thomas KS, Bardwell WA, Dimsdale JE. Which measures of obesity are related to depressive symptoms and in whom? Psychosomatics. 2008 Jan-Feb;49(1):23-8.
28. Guedes EP, Madeira E, Mafort TT, Madeira M, Moreira RO, Mendonça LM, et al. Body composition and depressive/anxiety symptoms in overweight and obese individuals with metabolic syndrome. Diabetol Metab Syndr. 2013 Dec 23;5(1):82.

29. Wang H, Liu A, Zhao T, Gong X, Pang T, Zhou Y, et al. Comparison of anthropometric indices for predicting the risk of metabolic syndrome and its components in Chinese adults: a prospective, longitudinal study. BMJ Open. 2017 Sep 18;7(9):e016062.

30. Rutten EP, Breyer MK, Spruit MA, Hofstra T, van Melick PP, Schols AM, et al. Abdominal fat mass contributes to the systemic inflammation in chronic obstructive pulmonary disease. Clin Nutr. 2010 Dec;29(6):756-60.

31. Sam S, Haffner S, Davidson MH, D'Agostino RB Sr, Feinstein S, Kondos G, et al. Relation of abdominal fat depots to systemic markers of inflammation in type 2 diabetes. Diabetes Care. 2009 May;32(5):932-7.

32. Bornstein SR, Schuppenies A, Wong ML, Licinio J. Approaching the shared biology of obesity and depression: the stress axis as the locus of gene-environment interactions. Mol Psychiatry. 2006 Oct;11(10):892-902.

33. Chrousos GP. The role of stress and the hypothalamic-pituitary-adrenal axis in the pathogenesis of the metabolic syndrome: neuro-endocrine and target tissue-related causes. Int J Obes Relat Metab Disord. 2000 Jun;24 Suppl 2:S50-5. 